\title{
Soğuk Şartlar Altındaki Bir Boruda MHD Nanoakışkanın Zorlanmış Taşınım ile Isı Transferi
}

\author{
Murat ERDEM ${ }^{* 1}$, Yasin VAROL ${ }^{2}$, Müjdat FIRAT ${ }^{3}$ \\ ${ }^{1}$ Elektrik ve Enerji Bölümü, Teknik Bilimler Meslek Yüksekokulu, Fırat Üniversitesi, Elazı̆g, Türkiye \\ ${ }^{2}$ Otomotiv Mühendisliği Bölümü, Teknoloji Fakültesi, Fırat Üniversitesi, Elazığg, Türkiye \\ ${ }^{3}$ Makine Eğitimi Bölümü, Teknik Eğitim Fakültesi, Fırat Üniversitesi, Elazı̆ğ, Türkiye \\ ${ }^{* 1}$ muratrdm01@ gmail.com, ${ }^{2}$ yvarol@ gmail.com, ${ }^{3}$ mujdatfirat@ gmail.com
}

\begin{abstract}
Öz: Mevcut çalışmada manyetik alan etkisi altındaki bir boruda $\mathrm{Al}_{2} \mathrm{O}_{3}-$ su nanoakışkanının 1sı transferi olgusu sayısal olarak incelenmiştir. Dış manyetik alan akışkan yönüne dik olarak uygulanmıştır. Yönetici denklemler ANSYS Fluent ticari yazılım programı ile çözülmüştür. Akışkan sıcaklığı (Ti) boru sıcaklığından (Tw) daha yüksek tutularak akışkanın soğuması sağlanmıştır. Reynolds sayısı (Re), Hartmann sayısı (Ha) ve nanoapartikül hacimsel oranı $(\varphi)$ sırasıyla, Re=10, 100, 500, 1000, $2000, \mathrm{Ha}=0,25,50,100$ ve $\varphi=0.01,0.03,0.05$ olarak seçilmiştir. Çalışmada, yerel Nusselt (Nux) ve ortalama Nusselt $(\mathrm{Nu})$ sayısı detaylı olarak incelenmiştir. $\mathrm{Re}=10$ hariç diğer Re sayılarında manyetik alan uygulanması ve nanopartikül eklenmesi hem yerel hem de ortalama Nu sayısını artırmıştır. Sabit Ha sayısı ve $\varphi$ değerinde Re sayısının artmasıyla 1sı transferi artmıştır. Sonuç olarak Re sayısı, Ha sayısı ve nanopartikül hacimsel oranıyla 1sı transferinin arttığı belirlenmiştir.
\end{abstract}

Anahtar kelimeler: Manyetohidrodinamik, Nanoakışkan, Zorlanmış taşınım, Isı transferi.

\section{Heat Transfer with Forced Convection of MHD Nanofluid in a Pipe Under Cold Conditions}

\begin{abstract}
In the present study, the heat transfer phenomena of $\mathrm{Al}_{2} \mathrm{O}_{3}$-water nanofluid in a pipe under the magnetic field effect have been investigated numerically. The external magnetic field is applied perpendicular to the fluid direction. Government equations are solved with ANSYS Fluent commercial software programmer. The fluid temperature (Ti) was kept higher than the pipe temperature (Tw), allowing the fluid to cool. Hartmann number (Ha), Reynolds number $(\mathrm{Re})$ and nanoparticle volume fractions $(\varphi)$ have been selected as $\mathrm{Re}=10,100,500,1000,2000, \mathrm{Ha}=0,25,50,100$ and $\varphi=0.01,0.03,0.05$, respectively. In the study, Local Nusselt ( $\mathrm{Nux}$ ) and average Nusselt number $(\mathrm{Nu})$ have been examined in detail. Except $\mathrm{Re}=10$, applying a magnetic field and adding nanoparticles in the other Re numbers have been increased both local and average Nu number. The heat transfer has raised with the increase Re numbers in the fixed Ha number and $\varphi$. As a result, it has been determined that the heat transfer increases with Re number, Ha number, and nanoparticles volume fraction.
\end{abstract}

Key words: Magnetohydrodynamics, Nanofluid, Forced convection, Heat transfer.

\section{Giriș}

Nanopartiküllerin 1Sı transferine olan etkisinin daha iyi anlaşılması için yapılan birçok bilimsel çalışma mevcuttur. Elektriksel iletkenliği olan akışkanların manyetik alan ile ısı transferini değiştirme tekniği literatürde son zamanlarda sıkça çalışılan öncü konulardan bir tanesidir. Nanoakışkan, nano boyuttaki parçacıkların temel akışkan içerisindeki süspansiyonudur. Bununla alakalı nanoakışkan terimi ilk kez Choi [1] tarafından kullanılmıştır. Konuyla alakalı bazı araştırmacılar düşük nanopartikül konsantrasyonlarında termal iletkenliğin yaklaşık \% 20'ye kadar çıkabileceğini kanıtlamışlardır [1-4]. Diğer bir uygulama alanı olan Manyetohidrodinamik (MHD), manyetik alan altında elektriksel iletkenliğe sahip olan sıvıların davranışını inceleyen disiplinler arası bir araştırma konudur. MHD ile ilgili ilk çalışma Hartmann (Ha) tarafindan yapılmıştır [5]. Hartmann, manyetik alana maruz iki paralel plaka arasında elektrik iletkenliğe sahip viskoz ve sıkıştırılamaz bir sıvının davranışını araştırmışıır. Bir dairesel kanal içindeki zorlanmış taşınım ile ısı transferi olayı da, güneş kolektörleri, enerji santralleri, yüksek performanslı kazanlar, soğutma-ısıtma sistemleri, kimyasal katalitik reaktörler ve diğer birçok akış hareketi ile ısı transferi uygulamaları gibi birçok teknolojik uygulamaların en önemli konularından biridir [610]. Literatürde, farklı nanopartikül tipi, nanopartikül hacimsel oranı, değişik geometri ve sınır şartları ile ilgili birçok çalışma mevcuttur. Bunlardan bazılarına aşağıda verilmiştir. Erdem ve Varol [11], Cu-su nanoakışkanına dış manyetik alan uygulayarak akış karakteristikleri ve 1 sı transferini incelemişlerdir. Çalışmada özellikle yüksek Re sayılarında, manyetik alan ve nanopartikül hacimsel oranının artmasıyla ısı transferinde iyileşme meydana

\footnotetext{
* Sorumlu yazar: muratrdm01@gmail.com. Yazarların ORCID Numarası: ${ }^{1} 0000-0003-0287-1881,{ }^{2} 0000-003-2989-7125,{ }^{3}$ 0000-00016978-9044
} 
geldiğini ortaya koymuşlardır. Erdem [12] değişik nanoakışkan tipleriyle yaptığı çalışmada manyetik alanın 1Sı transferini arttırmada çok etkili olduğunu göstermiştir. Ayrıca Erdem vd. [13], bir boruda lityum sıvısı için, Erdem ve Varol [14] sıvı PbLi17 üzerinde yaptıkları sayısal çalışmada manyetik alanın akışkanın 1sı transferini arttırdığını belirlemişlerdir. Öztürk [15], sabit 1Sı akısına maruz iki paralel plaka arasından, elektriksel iletkenliği olan bir viskoz akışkanın daimi, tam gelişmiş laminer ve bu akışa dik manyetik alanın varlığında isı transferini analitik olarak incelemiştir. Knudsen sayısı (Kn), Brinkman sayısı (Br) ve Hartmann sayısının hız, sıcaklık dağılımı ve 1sı transferi karakteristikleri üzerindeki etkilerini incelemiştir. Ha sayısının artmasıyla $\mathrm{Nu}$ sayının arttığını gözlemlermiştir. Ayrıca, Knudsen sayısı arttıkça, kanal duvarındaki sıcaklık atlamalarından dolayı Nu sayısının azaldığını tespit etmiştir.

Lu vd. [16], laminer ve türbülanslı akışlar için bir silindirik elektromanyetik akış ölçerin üç boyutlu MHD ile ilgili bazı simülasyonlarını ANSYS-FLUENT MHD modülünü kullanarak gerçekleştirmişlerdir. Her iki akış türü için elektrik alan, akım yoğunluğu ve bağlantı kablosu elektrotları boyunca elektrik potansiyeli verilerini değerlendirmişlerdir. Sonuç olarak, elektrotlar üzerinde hesaplanan elektrik potansiyeli farkının küçük Ha sayısı durumları için analitik değerlerle uyumlu olduğu, ayrıca, türbülanslı akışın karşıt-kesitli akış ölçerdeki elektrik potansiyeli dağılımının laminer akışınkinden daha üniform olduğunu savunmuşlardır. Sun vd. [17], iletkenliği olan bir akışkan içerisinde, belirli bir mesafede kendileri de iletken olan iki parçacığın çok güçlü bir manyetik alan altında, parçacıklar arası etkileşim ile katı-sıvı etkileşimini incelemek için nümerik bir model geliştirmişlerdir. Modeli sonlu hacim metoduna dayanan ticari paket programı ANSYS-FLUENT ile oluşturmuşlardır. Tek bir küresel parçacığın sürükleme kuvvetinin sürüklenen bir akış sınırında yaklaşık $\% 15$ kadar artabileceği ve indüklenen manyetohidrodinamik etkileşim kuvvetinin akış alanı ve manyetik akı yoğunluğuna büyük ölçüde bağlı olduğunu savunmuşlardır. Nayak vd. [18], sıcaklığa bağlı viskozite ile tel kaplama analizi için üçüncü derece bir sıvının 1sı transferi ve sürekli MHD akışı nümerik ve analitik olarak çalışmışlardır. Manyetik alan uygulanmaksızın büyük $\mathrm{Br}$ sayılarının sıcaklık dağılımını artırdığı, sabit viskozite durumunda artan manyetik alanın akışkan hızını azalttığını açıklamışlardır. Reynolds modelinde ise, akışkanın newtonsal olmayan özelliği sıcaklığa bağlı değişebilen viskozite ile birlikte hızı arttırmak için uygun bir parametre olduğu gözlemlenmiştir. Muthuraj ve Srinivas [19], içinde gözenekli madde bulunan asimetrik dalgalı bir kanalda, MHD titreşimli akışın hareketini analitik olarak incelemişlerdir. Akış hızının radyasyon parametresi, Grashof $(\mathrm{Gr})$ ve Pecklet (Pe) sayısındaki artışla artarken, Ha sayısının artmasıyla azaldığını belirtmişlerdir. Anwar Bég vd. [20] tarafından, Darcian (Da) gözenekli bir ortama sahip iki paralel plaka arasında viskoz, sıkıştırılamaz manyetohidrodinamik bir akış için nümerik bir çözüm geliştirilmiştir. Da değeri ve basınç gradyanın artmasıyla hem birincil hem de ikincil hız alanının arttığı, fakat bu alanların Ha sayısının armasıyla azaldığını gözlemlenmişlerdir. Bandyopadhyay ve Layek [21], dar bir kanalda manyetohidrodinamik akışı hem sürekli hem de vurmalı akış için sonlu fark metodunu kullanarak zamana bağlı nümerik olarak çözmüşlerdir. Akış ayrılma bölgesinin manyetik parametrenin artmasıyla azaldığını, vurmalı akıştaki duvar kayma gerilmesi tepe değerinin zamanla değiştiği ve bu değerin maksimum akış hızında en büyük değeri aldığını, her iki akışşartlarında (sürekli ve vurmalı) manyetik parametrenin sınır tabaka ayrışmasının uygulanan dış manyetik alan ile kontrol edilebileceğini rapor etmişlerdir. Huang ve Li [22], üstü açık dikdörtgen bir kanalda, kanalın altına yarı küresel çıkıntılı duvarlar (protrusion walls) yerleştirerek 1Sı transfer artırımını $\left(\mathrm{Nu} / \mathrm{Nu}_{0}\right)$, akış karakteristikleri, sürtünme kayıplarını $\left(f / f_{0}\right)$ ve termal performansı sayısal olarak incelemişlerdir. Manyetik alan yoğunluğu $30 \leq \mathrm{Ha} \leq 70$ arasında seçmişlerdir. Çıkıntıların 1sı transfer katsayısını artırdığı ve Ha sayısııın artmasının bu katsayının azalttığını elde ettikleri sonuçlarla ortaya koymuşlardır. Aminfar vd. [23], dikey bir halkada, manyetiklenme özelliğine sahip ferroakış zorlanmış taşınım kritik 1sı akısı üzerindeki manyetik alanın etkisini deneysel olarak incelemişlerdir. Deneyde temel akışkan olarak su, nanopartikül olarak $\mathrm{Fe}_{3} \mathrm{O}_{4}$ kullanılmıştır.

Benzer şekilde doğal taşınım üzerinde Kefayati [24], bir dış manyetik kaynak varlığında lineer olarak 1sıtılımış bir oyukta ferroakışkan doğal taşınım 1sı dağılımının etkisini Lattice Boltzmann Methodu (LBM) yardımıyla nümerik olarak çalışmıştır. Çalışma sıvısı olarak gazyağı ve nano ölçekli kobalt parçacıklarının eklenmesiyle oluşan koloit karışımını oluşturmuştur. Sonuçlar, çeşitli Rayleigh (Ra) sayıları için ferromanyetik parçacıkların artması ısı transferini azalttığını göstermiştir. Sheikholeslami ve Ganji [25], sinüzoidal sıcak duvar ile yarı halka bir oyukta manyetik nanoakışkan ve ısı transferi üzerinde, dıştan uygulanan manyetik alanın etkisini nümerik olarak incelemişlerdir. Nu sayısının, Ra sayısı ve nanopartikül hacimsel oranının artmasıyla arttığı ve Ha sayısının artmasıyla azaldığı vurgulanmıştır. Yazarlar ayrıca, düşük Ra sayısı için 1sı transferi artırımının, Ha sayısının artan bir fonksiyonu olduğunu ortaya koymuşlardır. Malvandi vd. [26], dikey bir halka boruda $\mathrm{Al}_{2} \mathrm{O}_{3}$-su ile dolu nanoakışkanın MHD karma taşınım üzerinde nümerik bir çalışma gerçekleştirmişlerdir. Borunun iki tarafina 1S1 akısı uygulanmıştır. Nanopartikül göçünün etkisini hesaplamak için Brownian hareket yöntemi kullanılmıştır. Isı transferi artırımında bir avantaj olarak görülen nanoakışkanın, manyetik alan varlığında 1sı 
transferini azaltan bir parametre olduğu, fakat temel akışta Ha sayısının artmasıyla 1sı transferinin arttığı ortaya konulmuştur.

Nanoakışkana manyetik alan uygulanması ile 1Sı transferi ve akış karakteristiklerinin incelenmesi günümüzde literatürde çok çalışılan konulardandır. Dünya nüfusunun artması ile enerji kaynaklarının tükenmesi insanoğlunu sürekli yeni isı transferi tekniklerini araştırmaya sevk etmektedir. Bunlardan bir tanesi de nanopartikül eklenmesi ve manyetik alan şiddeti ile akışkanın kontrol edilerek 1sı transferini iyileştirilmesi tekniğidir. Bu amaçla mevcut çalışmada, manyetik alana maruz bırakılan bir boruda $\mathrm{Al}_{2} \mathrm{O}_{3}$-su nanoakışkanı 1sı transferi açısından incelenmiştir. Bunun için Re sayısı, Ha sayısı ve nanopartikül hacimsel oranının etkisi detaylı olarak incelenmiş ve her bir parametrenin etkisi ayrı bir Şekil içerisinde gösterilerek hangi parametrenin daha baskın olduğunun tespit edilmesi amaçlanmıştır. Böylece, etkili olan parametre daha net olarak belirlenmiştir. Nanoakışkanın manyetik alan kuvveti ile kontrol edilebilmesinde ve yüksek Re sayılarında 1sı transferini artırmada çok etkili bir yöntem olduğu sonucu ortaya çıkmaktadır.

\section{Materyal ve Metot}

\subsection{Problem Tanımlanması ve A $\breve{g}$ Yapısı}

Bu çalışmayı analiz etmek için üç boyutlu dairesel bir kanal kullanılmıştır. Kullanılan boru modeli Şekil 1'de gösterilmiştir. Boru çapı 10,92 mm'ye karşılık gelen, boru kalınlığ $0.89 \mathrm{~mm}$ standart 1/2" plastik boru kullanılmış ve malzeme özellikleri programda buna göre tayin edilmiştir. Akışkan giriş ve duvar sıcaklıkları sırasıyla Ti=50 ve $\mathrm{Tw}=30^{\circ} \mathrm{C}$ olarak seçilmiştir.

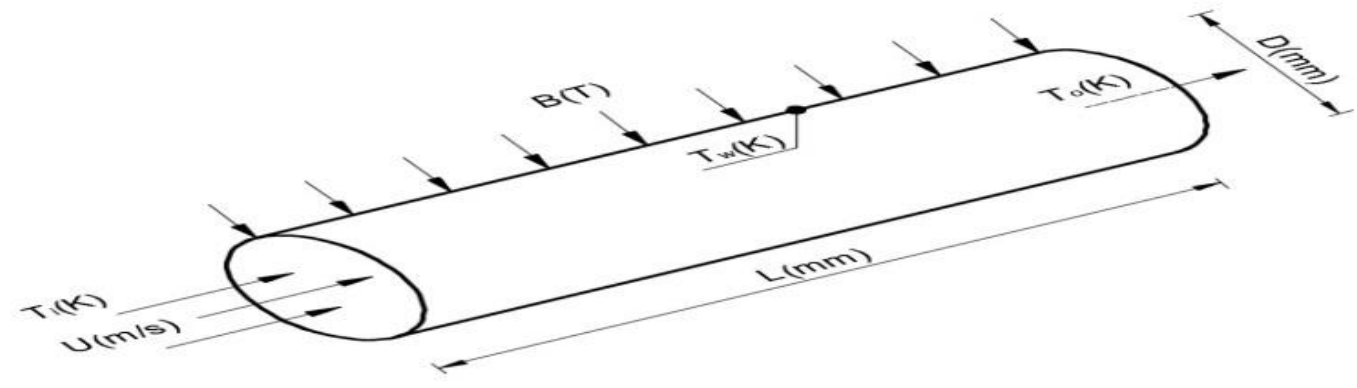

Şekil 1. Üç boyutlu dairesel kanal modeli (Ti: Akışkan giriş sıcaklığı, U=V: Akışkan giriş hızı, B: Manyetik alan şiddeti, Tw: Cidar sıcaklığı, To: Çevre sıcaklığı, L: Boru uzunluğu, D: boru çapı)

Boru ANSYS-FLUENT’te beş katı parçaya bölünerek oluşturulmuştur. Borunun ortasına kare-karşıt kesitli bir geometri ile ayrılarak borunun bölünmesi sağlanmıştır. Bu şekilde ağ yapısı çok daha kaliteli olmaktadır. Bu ağ yapısı Şekil 2'de gösterilmiştir. Şekilde görüldüğ̈̈ gibi ă̆ yapısında herhangi bir sapma (yamuk, yan, birbirini kesme vb.) yoktur. Literatürde bunun programdaki zorluklarından dolayı ağ yapısı genelde tek parça olarak oluşturulmaktadır. Ancak bu yöntem bölünmüş ağ yapısı kadar verimli değildir. Bu yüzden geometrinin bölünerek oluşturulması önerilmektedir. Bununla ilgili daha kapsamlı bilgiler Erdem [12] tarafından ispatlanmıştır. Çalışmada kullanılan ağ yapısının düğüm sayısı ve hücre sayısı sırasıyla 202669 ve 194000 'dir. Mesh Orthogonal (dörtgensel) ve Skewness (sapma) değerleri de sirasıyla 0. 0.97116 ve 8.8444e-002'dir. Orthogonal kalitesi 1 değerine yaklaştıkça mesh kalitesi de aynı oranda artmaktadır. Bu veriler literatüre göre oldukça iyi olduğu düşünülebilir. Burada geometrinin bölünerek yapılmasının etkisi oldukça büyüktür.

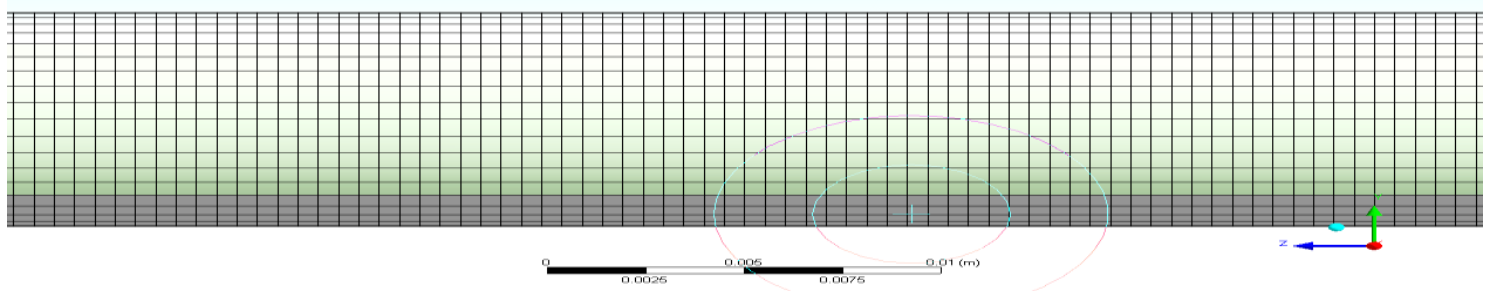

Şekil 2. Çalışmada kullanılan ağ yapısı 


\subsection{Sayısal Hesaplamalar}

ANSYS-FLUENT ticari yazılım programının içinde mevcut olan MHD modülü ile bu sayısal çalışma gerçekleştirilmiştir. Denklemler sonlu hacim tekniği ile çözülmüştür. Basınç-hız çifti için daha uygun olduğu düşünülen SIMPLE algoritması kullanılmıștır. Boru içerisindeki akıșkan, Newtonyen, sıkıștırılamaz ve laminar olarak kabul edilmiştir. Nanopartiküller küresel-şekilli boyut olarak çok küçük olduğundan nanoakışkan tek bir faz gibi davranmaktadır. Bu yüzden hesaplamalar tek fazlı akışkan olarak gerçekleştirilmiştir.

Boyutlu Navier-Stokes denklemleri Eş. 1-3 ile belirlenmektedir [27,28]:

$\nabla . \vec{V}=0$

$(\vec{V} . \nabla) \vec{V}=-\frac{1}{\rho_{n f}} \nabla P+v_{n f} \nabla^{2} \vec{V}+\frac{1}{\rho_{n f}} \vec{F}$

$(\vec{V} \cdot \nabla) \vec{T}=\alpha_{n f} \nabla^{2} \vec{T}$

$\vec{F}$, Lorentz kuvvetinden kaynaklanan kaldırma ve cisim kuvveti Eş. 4 ile ifade edilir [27, 29].

$\vec{F}=\vec{g}_{y}(\sigma \beta)_{n f}\left(\vec{T}-T_{0}\right)+\vec{J} x \vec{B}$

Eş. 4 'teki son terim Lorentz kuvveti olarak tanımlanmakta ve sıvı hareketine neden olmaktadır.

$\vec{J}$, elektrik akım yoğunluğu Ohm yasası ile bulunmuştur:

$\vec{J}=\rho_{n f}(\vec{E}+\vec{V} x \vec{B})$

$\vec{E}$, DC elektrik akımıdır ve $\vec{B}$, z yönündeki manyetik alandır. Böylece, manyetik alan ve elektrik akımı birbirine diktir ve bu da x ve y yönlerinde Lorentz kuvvetine neden olmaktadır. Baz akışkan ve nanopartiküllerin termofiziksel özellikleri Kaynak [12]'den alınmıştır. Ti $=50^{\circ} \mathrm{C}$ referans giriş sıcaklığında nanoakışkanın termofiziksel özellikleri aşağıdaki formüller yardımıyla hesaplanır.

Nanoakışkanın yoğunluğu Eş. 6 ile hesaplanmaktadır.

$\rho_{n f}=(1-\varphi) \rho_{f}+\varphi \rho_{s}$

Nanoakışkanın özgül 1sı kapasitesi Eş. 7 ile bulunur.

$\left(\rho c_{p}\right)_{n f}=(1-\varphi)\left(\rho c_{p}\right)_{f}+\varphi\left(\rho c_{p}\right)_{s}$

Nanoakışkanın termal iletkenliği $\left(\mathrm{k}_{\mathrm{nf}}\right)$ takip edilen Eş. 8, Maxwell-Garnett's (MG modeli) ile hesaplanır.

$\frac{k_{n f}}{k_{f}}=\frac{k_{s}+2 k_{f}-2 \varphi\left(k_{f}-k_{s}\right)}{k_{s}+2 k_{f}+\varphi\left(k_{f}-k_{s}\right)}$

Eş. 9 ve Eş. 10, sırasıyla nanoakışkanın dinamik viskozitesini (Brinkman modeli) ve Ha sayısını hesaplamak için

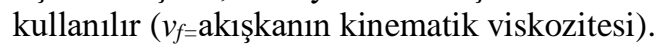

$\mu_{n f}=\frac{\mu_{f}}{(1-\varphi)^{2.5}}$

$H a=B R \sqrt{\frac{\sigma_{n f}}{\rho_{n f} f_{f}}}$ 
Yerel Nusselt sayısı, sıcak duvarın kenarındaki ısı dengesinden (Eş. 11) elde edilmektedir [1].

$N u_{x}=\frac{k_{n f}}{k_{f}} \frac{(\partial T / \partial n) L}{\left(T_{w}-T_{i}\right)}$

Ortalama Nusselt sayısı (Nu), yerel Nusselt sayılarının kanal uzunluğu (L) boyunca entegre edilerek hesaplanır (Eş. 12).

$N u=\frac{1}{L} \int_{0}^{L} N u_{x} d x$

\section{Sonuçlar ve Tartı̧̧ma}

Sıcak akışkanla duvar arasındaki sıcaklıktan hesaplanan yerel $\mathrm{Nu}$ değerlerinin boru uzunluğu boyunca değişimleri çalışma kapsamında irdelenmiştir. Detaylı olarak incelenen çalışmadan Re sayısı, Ha sayısı ve nanopartikül hacimsel oranının $\mathrm{Nu}$ değerlerini önemli oranda iyileştirdiği anlaşılmıştır. Kapsamlı sonuçlar grafik olarak sunulmuştur.

Farklı nanopartikül hacimsel oranlarındaki $\mathrm{Al}_{2} \mathrm{O}_{3}$-su nanoakışkanına ait yerel $\mathrm{Nu}$ sayılarının boru uzunluğu boyunca Ha sayısı değişimleri Şekil 3’te verilmiştir. En düşük Re sayısına sahip akışkan için kanalın yaklaşık $0.04 \mathrm{~m}$ mesafesine kadar yerel $\mathrm{Nu}$ sayısının, manyetik alan kuvvetinin etkisi ile saf akışkana göre önce arttığ ve bu noktadan sonra değerlerin azaldığı tespit edilmiştir. $\mathrm{Bu}$ değerler $\mathrm{Ha}=25$ için $\mathrm{Nu}_{\mathrm{X}}=5.845, \mathrm{Ha}=50$ için $\mathrm{Nu}_{x}=6.231$, $\mathrm{Ha}=100$ için $\mathrm{Nu}_{\mathrm{X}}=6.750$ değerinden sonra azalarak saf akışkandan daha az değerler almaya başlamıștır $(\mathrm{Re}=10$ $\varphi=0.01) . \mathrm{Re}=10$ ve $\varphi=0.03$ parametresi için, sırasıyla $\mathrm{Ha}=25,50$ ve 100 değerlerinde $\mathrm{Nu}_{X}$ sayıları sırasıyla $\mathrm{Nu}_{\mathrm{X}}=6.280,6.832$ ve 7.436 değerinden sonra saf akışana göre azalmaya başlamıştır. Aynı şekilde $\mathrm{Re}=10$ ve $\varphi=0.05$ için, sırasıyla $\mathrm{Ha}=25,50$ ve 100 için yerel $\mathrm{Nu}$ değerleri, $\mathrm{Nu}_{\mathrm{x}}=6.799,7.426,7.973$ değerlerine ulaştıktan sonra saf akışkana göre azalma eğilimine geçmiştir. Bu değişim, çalışma kapsamında elde edilen en önemli sonuçlardan bir tanesidir. Bu durumun nedeni, akışkan hızının oldukça düşük olması ve manyetik alan kuvveti ile akışkan hızının daha da azalmasından kaynaklanmaktadır. Başka bir değişle taşınım olayının belirli bir noktadan sonra çok az gerçekleşmesi olarak da açıklanabilir. Burada doğal taşınım olayına benzer bir sonuç ortaya çıkmıştır. İletim taşınımdan daha baskın olmuştur. Ayrıca $\mathrm{Re}=10$ parametresinde manyetik alanın 1 sı transferini arttırdığı, ancak manyetik alan kuvvetlerinin birbirlerine göre neredeyse hiç 1sı transferini değiştirmediği tespit edilmiştir. $\operatorname{Re}=100$ 'de manyetik alan şiddetinin yerel Nu sayısını artırdığı ve kanalın sonuna doğru aşağı-yukarı birbirine eşitlendiği görülmektedir. Diğer üç Re sayısında $(500,1000,2000)$ Ha sayısının artmasıyla birlikte yerel $\mathrm{Nu}$ sayılarında artış olduğu daha net olarak anlaşılımış ve kanalın girişinden çıkışına kadar bu artış düzenli olarak devam etmiş̧tir. Re sayısının artmasıyla orantılı olarak meydana gelen yerel $\mathrm{Nu}$ sayısı değişimi daha fazla olmuştur. Kanalın tam girişindeki yerel $\mathrm{Nu}$ sayılarının değerleri, nanopartikülün eklenmesinin isı transferini iyileştirdiğini kanıtlamaktadır.

Nanopartikül eklenmesi ile akışkan üzerinde meydana gelen 1sı transferi olayını daha net anlamak için, Şekil 4'te $\mathrm{Al}_{2} \mathrm{O}_{3}$-su nanoakışkanının farklı nanopartikül hacimsel oranlarında yerel $\mathrm{Nu}$ sayılarının karşılaştırılmaları gösterilmiştir. Manyetik alan şiddetinin olmadığı $(\mathrm{Ha}=0)$ ve olduğu $(\mathrm{Ha}=25,50$ ve 100$)$ durum ile beş farklı Re sayısı $(\operatorname{Re}=10,100,500,1000,2000)$ için sonuçlar gözlemlenmiştir. Şekil incelendiğinde nanopartiküllerin 1sı transferi üzerinde çok etkili olduğu net şekilde görülmüştür. Nanopartikül hacimsel oranın yüksek değerlerinde yerel $\mathrm{Nu}$ sayısı daha fazla çıkmıştır. Diğer grafiklerin tümünde kanal boyunca nanopartiküllerin katkısıyla isı transferinin iyileştiği belirlenmiştir. Yerel $\mathrm{Nu}$ ile ilgili daha önceki sonuçlarda açıklandığı gibi bu durumun akışkanın çok yavaş hareket etmesi ile akışkan taşınımının çok az meydana gelmesinden kaynaklandığı düşünülmektedir. Yani iletimle olan 1S1 transferi mekanizmasının taşınımla olan 1S1 transferine göre daha baskın olduğu sonucunu ortaya çıkarmıştır.

Şekil 5'de $\mathrm{Al}_{2} \mathrm{O}_{3}$-su nanoakışkanının üzerinde farklı Ha sayıları ve nanopartikül hacimsel oranlarında Re sayısı etkisi sunulmuştur. Ortaya çıkan sonuçlar beklenildiği gibi Re sayısının ısı transferini arttırmada çok etkili olduğu belirlenmiştir. Çalışılan bütün parametrelerde Re sayısının artmasıyla daha fazla akışkan taşındığından isı transferi çok ciddi bir oranda artmıştır. 
Soğuk Şartlar Altındaki Bir Boruda MHD Nanoakışkanın Zorlanmış Taşınım ile Isı Transferi
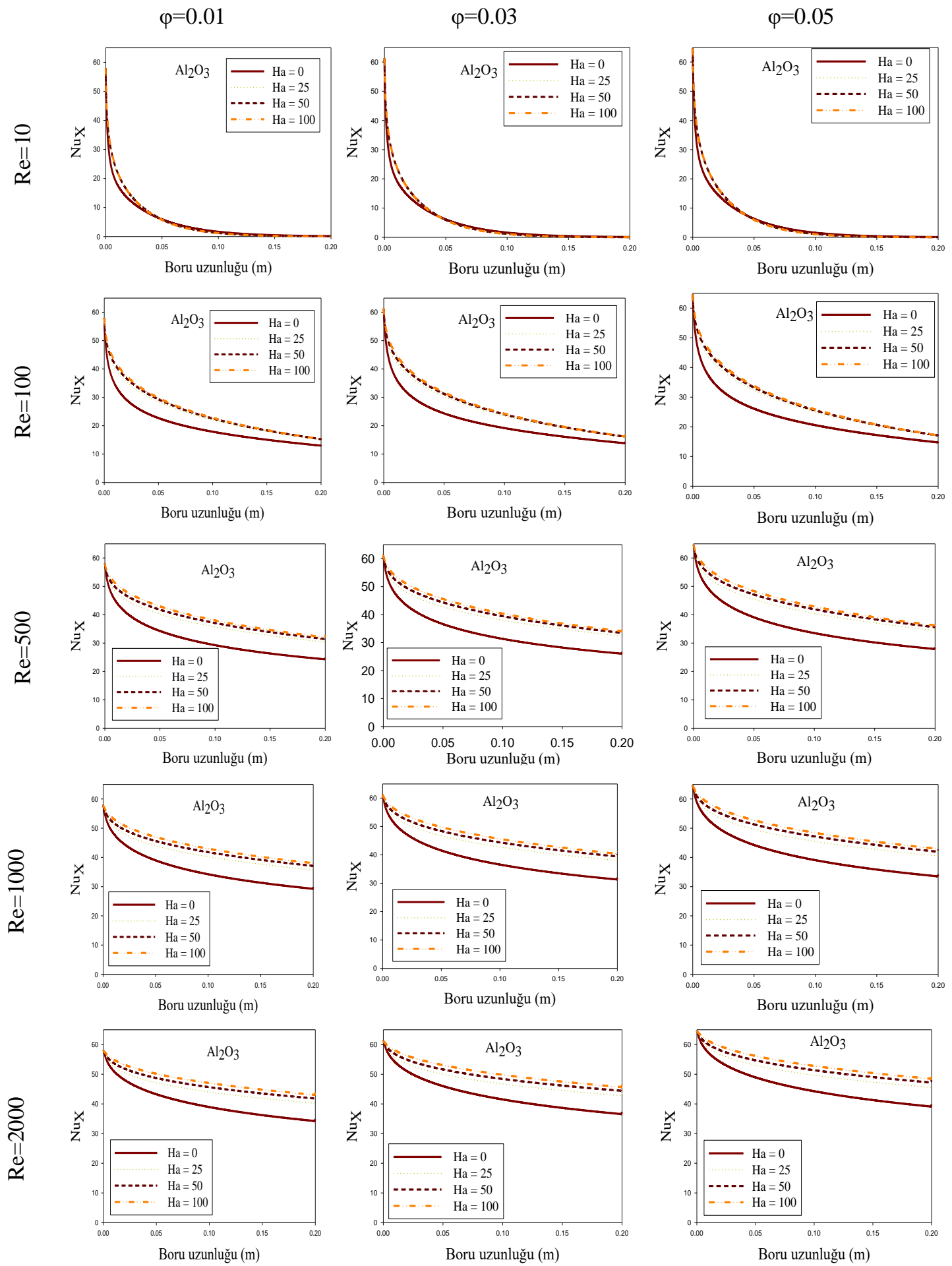

Şekil 3. $\mathrm{Al}_{2} \mathrm{O}_{3}$ - su nanoakışkanının boru uzunluğu boyunca yerel Nu sayısının Ha sayısı ile değişimi 
$\mathrm{Ha}=0$
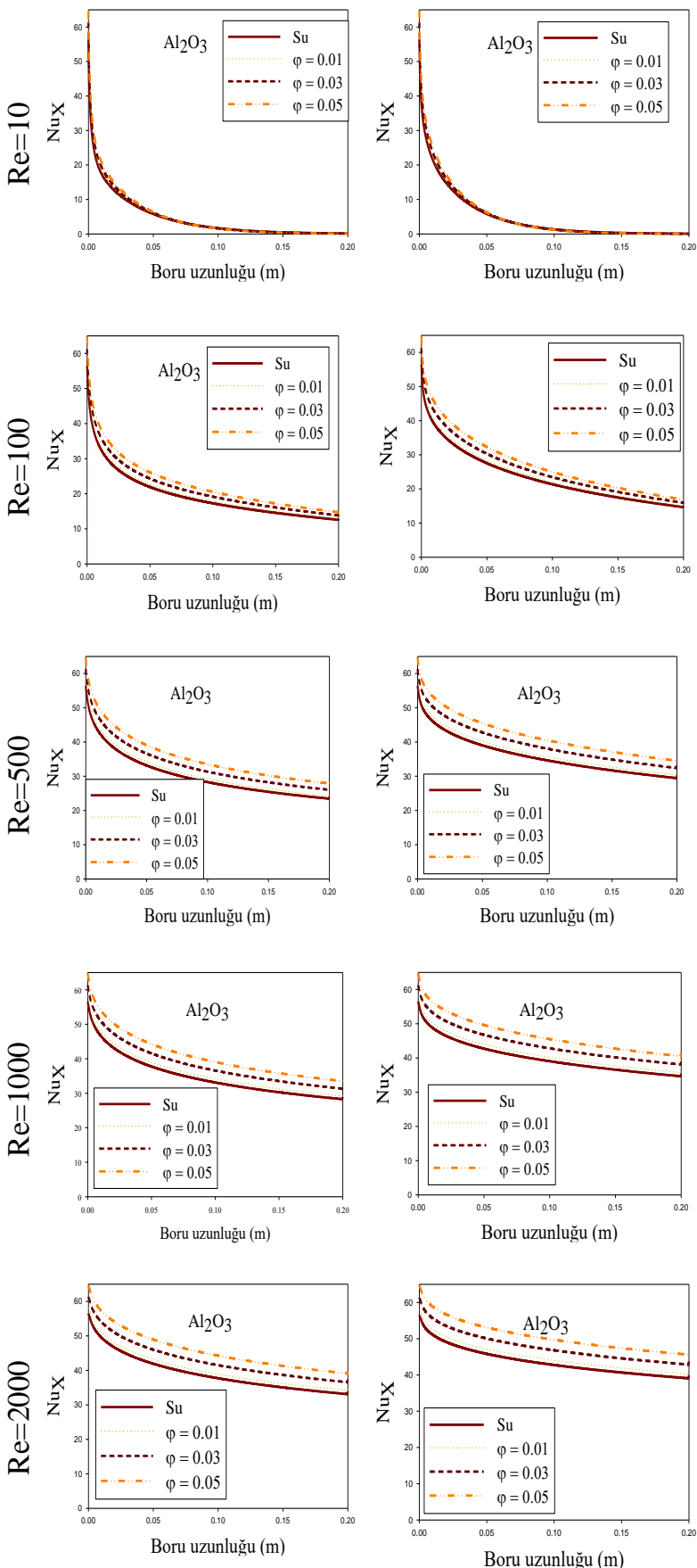

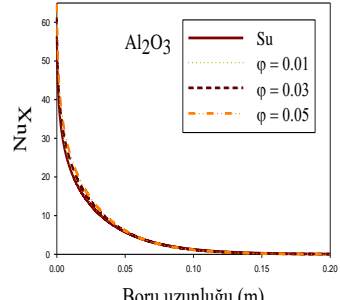

$\mathrm{Ha}=50$
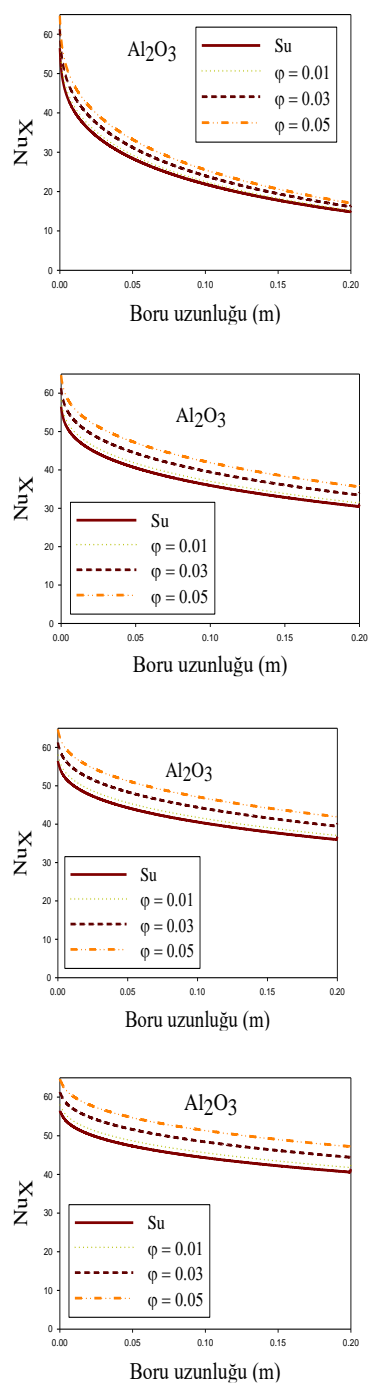

$\mathrm{Ha}=100$
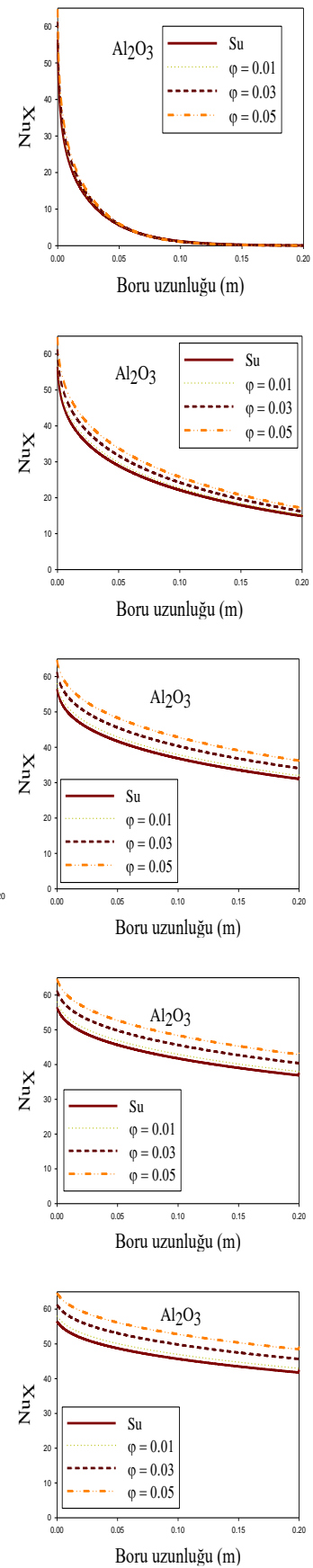

Şekil 4. $\mathrm{Al}_{2} \mathrm{O}_{3}$ - su nanoakışkanının kanal boyunca yerel Nu sayılarının nanopartikülle değişimi 

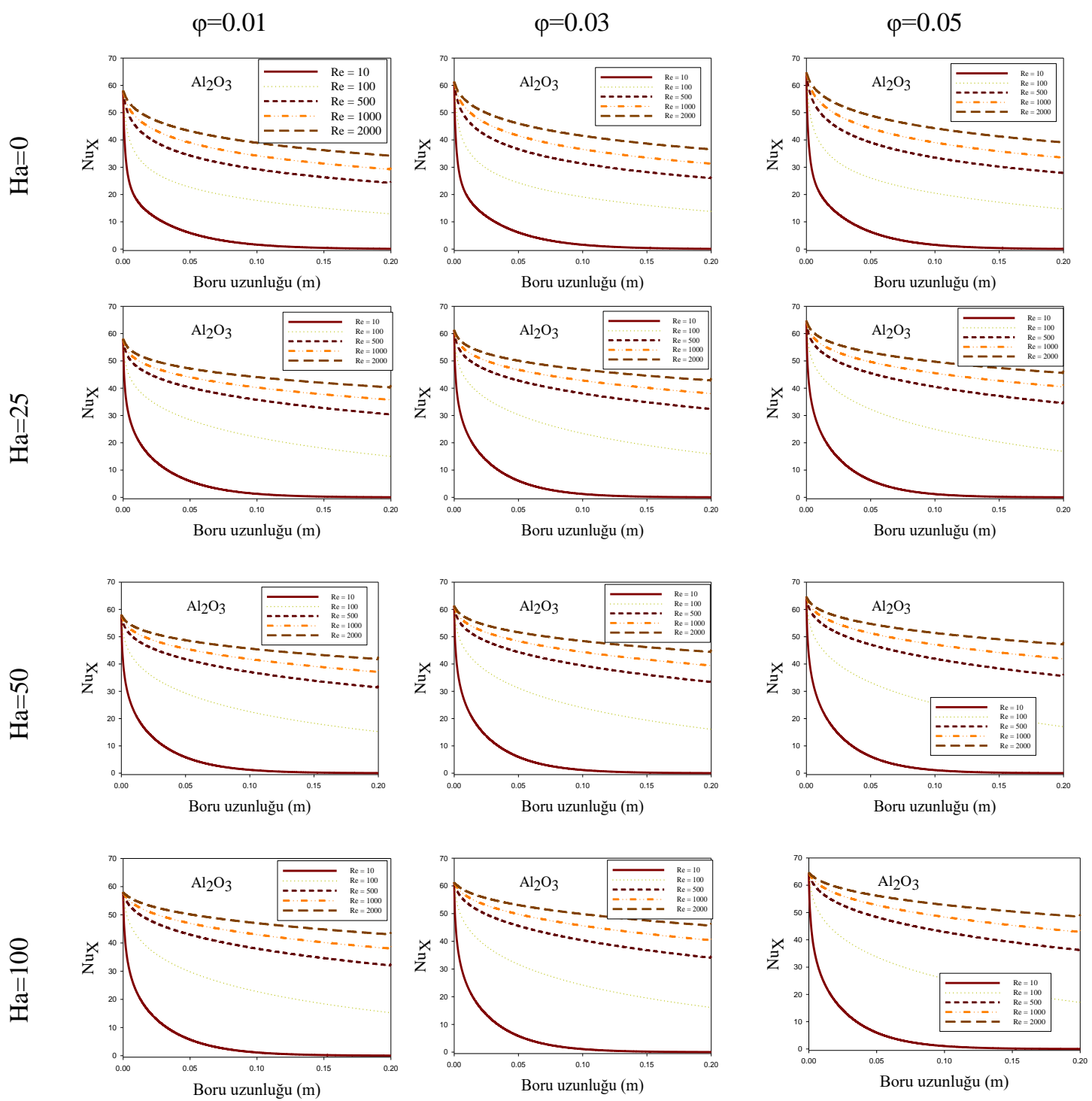

Şekil 5. $\mathrm{Al}_{2} \mathrm{O}_{3}-$ su nanoakışkanının kanal boyunca yerel $\mathrm{Nu}$ sayılarının Re sayısıyla değişimi

Elde edilen ortalama Nu değerlerinin nanopartikül hacimsel oranıyla değişimi farklı Re ve Ha değerleri için Şekil 6'da verilmiştir. Re=10 hariç bütün çalışma parametrelerinde Ha sayısı, Re sayısı ve nanopartikül hacimsel oranı ortalama $\mathrm{Nu}$ sayısı üzerinde arttırıcı bir etki meydana getirmiştir. Ancak $\mathrm{Re}=10$ 'da manyetik alan ilk uygulandığında önce 1sı transferi artmış, daha sonra artma yavaş şekilde devam etmiş, fakat Ha=100'de 1sı transferi azalmıştır. Bunda daha önce bahsedilen akışkanın çok yavaş hareket etmesi durumu etkili olmuştur. Yerel $\mathrm{Nu}$ sayılarında da 1sı transferinin kanalın yaklaşık 1/4’ünden sonra azalma eğilimi gösterdiği ve toplamda iletim değerlerinin taşınım değerlerinden daha fazla olduğu belirtilmişti. En düşük ortalama Nu sayısı, su $(\varphi=0), \operatorname{Re}=10$ ve $\mathrm{Ha}=0$ için $\mathrm{Nu}=8.753$ iken, en yüksek değer $\varphi=0.05$, $\mathrm{Re}=2000$ ve $\mathrm{Ha}=100$ için $\mathrm{Nu}=104.843$ olarak elde edilmiştir. Burada düşük Re sayısından sonra elde edilen diğer sonuçlar Heidary vd. [6] ile Erdem ve Varol [11] tarafından, ortalama $\mathrm{Nu}$ sayısı, nanopartikül hacimsel oranı ve Ha sayısı arasındaki ilişkiyi incelerken gerçekleştirdikleri sayısal sonuçlarla oldukça uyumlu bir eğilim göstermiştir. 
Murat ERDEM, Yasin VAROL, Müjdat FIRAT

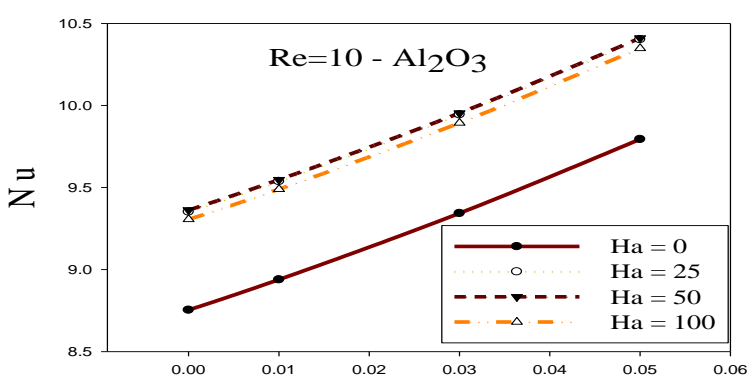

Nanopartikül hacimsel oranı $(\varphi)$

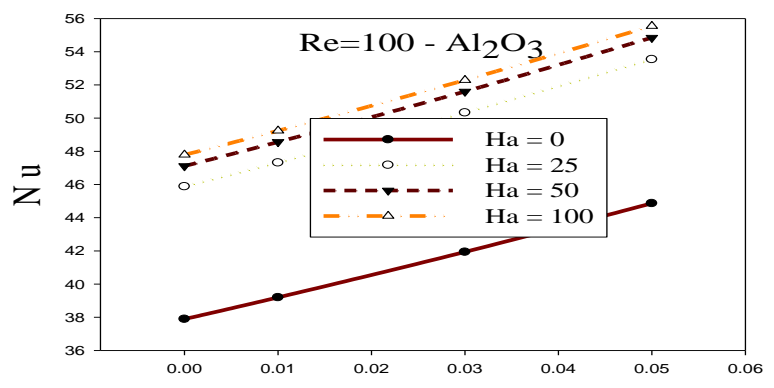

Nanopartikül hacimsel oranı $(\varphi)$

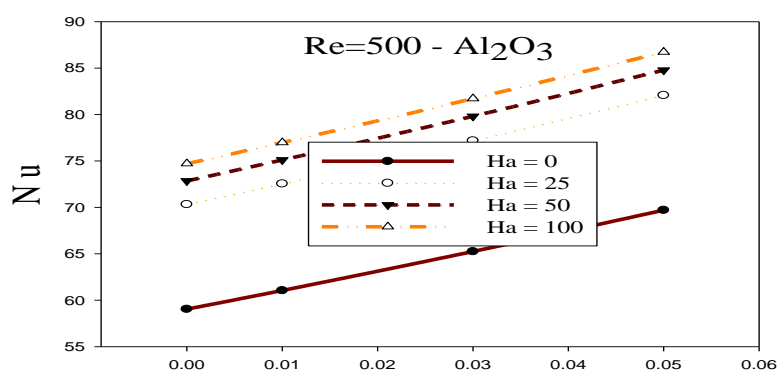

Nanopartikül hacimsel oranı $(\varphi)$

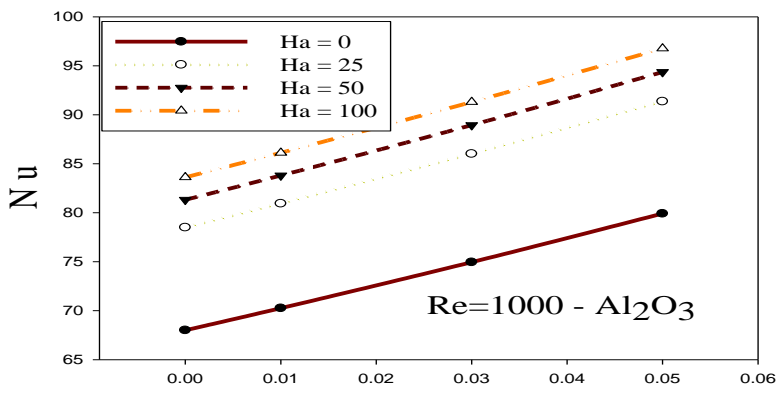

Nanopartikül hacimsel oranı $(\varphi)$

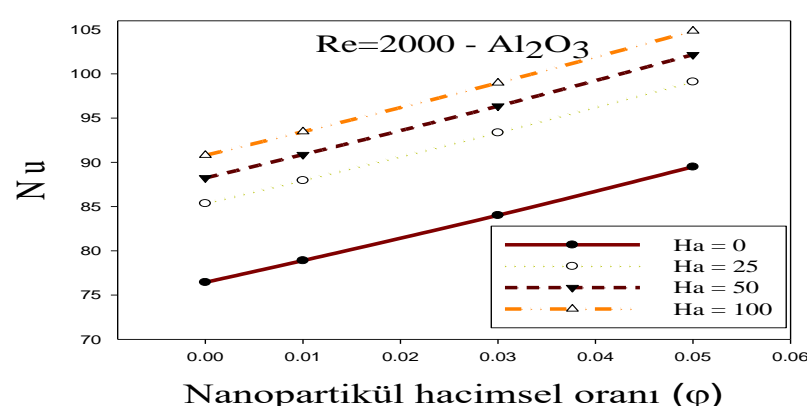

Şekil 6. $\mathrm{Al}_{2} \mathrm{O}_{3}$-su nanoakışkanının ortalama $\mathrm{Nu}$ sayısı üzerinde $\varphi$, Re ve Ha etkisi 


\section{Sonuç}

$\mathrm{Al}_{2} \mathrm{O}_{3}$-su nanoakışkanı için 1Sı transferi olayı, manyetik alana maruz olan bir boruda sayısal olarak incelenmiştir. Farklı Re, Ha ve nanopartikül hacimsel oranlarının etkisini görmek için elde edilen sonuçlar, bu parametrelerin 1sı transferi üzerinde çok etkili olduğunu göstermektedir. Beklenildiği gibi Re sayısı ile hem yerel hem de ortalama Nusselt sayısı artmıştır. $R e=100,500,1000$ ve 2000 için, manyetik alan ve nanopartikül eklenmesi ile birlikte yerel ve ortala $\mathrm{Nu}$ sayısı artmıştır. $\mathrm{Re}=10$ için manyetik alan ve nanopartikül hacimsel oranın artması ile birlikte yerel Nu sayılarında hem azalma hem de artma meydana gelmiștir, bu durum (azalma) akışkanın çok az hareket ettiğinden kaynaklanmaktadır. Ancak, $R e=10$ şartında ortalama Nu sayısı nanopartikül ile artarken, Ha sayısının 50'den 100'e geçerken azalma meydana geldiği tespit edilmiştir. Bu durumda çalışma kapsamında elde edilen önemli sonuçlardan bir tanesidir. Nanoakışkanların etkisini daha iyi anlamak için farklı geometrilerde, farklı sınır şartlarında hem deneysel hem de sayısal çalışmalar gerçekleştirilerek daha önemli sonuçların elde edilmesi önerilmektedir.

\section{Teşekkür}

$\mathrm{Bu}$ sayısal çalı̧̧ma Fırat Üniversitesi Bilimsel Araştırmalar Proje biriminin (FUBAP) katkılarıyla gerçekleştirilmiştir (Proje No: TEKF.15.01). Yazarlar bu projeye desteklerinden dolayı Fırat Üniversitesine teşekkür ederler.

\section{Kaynaklar}

[1] Choi SUS, Eastman JA. Enhancing thermal conductivity of fluids with nanoparticles. No. ANL/MSD/CP-84938, CONF951135-29, Argonne National Lab., IL, 1995.

[2] Lee S, Choi SUS, Li S, Eastman JA. Measuring thermal conductivity of fluids containing oxide nano-particles ASME J Heat Transfer 1999; 121: 280-289.

[3] Eastman JA, Choi SUS, Li S, Yu W, Thompson LJ. Anomalously increased effective thermal conductivities of ethylene glycol-based nano fluids containing copper nano-particles. App Phys Lett 2001; 78: 718-720.

[4] Xuan Y, Li Q. Heat transfer enhancement of nano-fluids. Int J Heat Fluid Flow 2000; 21: 58-64.

[5] Hartmann J. Theory of the laminar flow of an electrically conductive liquid in a homogeneous magnetic field, Mathematisk Fysiske Meddelelser. 1937; 15(6): 1-28.

[6] Heidary H, Hosseini R, Pirmohammadi M, Kermani MJ. Numerical study of magnetic field effect on nano-fluid forced convection in a channel. J magn magn Mater 2015; 374: 11-17.

[7] Wang BX, Du JH, Peng XF. Internal natural, forced and mixed convection in fluid-saturated porous medium. Trans Phenom Porous Media 1998; 357-382.

[8] Demirel Y, Al-Ali HH, Abu-Al-Saud BA. Enhancement of convection heat-transfer in a rectangular duct. Appl Energy 1999; 64: 441-451.

[9] Cheng KC, Hong SW. Effect of tube inclination on laminar convection in uniformly heated tubes for flat-plate solar collectors. Sol Energy 1972; 13: 363-371.

[10] Esfe MH, Saedodin S, Malekshah EH, Babaie A. Mixed convection inside lid-driven cavities filled with nanofluids. J Therm Anal Calorim 2019; 135: 813-859.

[11] Erdem M, Varol Y. Numerical investigation of heat transfer and flow characteristics of MHD nano-fluid forced convection in a pipe. J Therm Anal Calorim 2020; 139(6): 3897-3909.

[12] Erdem M. Nano parçacık katkılı manyetohidrodinamik akışın deneysel ve sayısal incelenmesi. Doktora Tezi, Fırat Üniversitesi Fen Bilimleri Enstitüsü, 2019.

[13] Erdem M, Fırat M, Varol Y. Dairesel bir kanalda soğutma şartları altında MHD sıvı lityum akışın sayısal olarak incelenmesi. Pamukkale Üniversitesi Mühendislik Bilimleri Dergisi 2018; 24(1): 30-35.

[14] Erdem M, Varol Y. Numerical investigation of PbLi17 fluid flow forced convection heating under magnetic field. Journal of Materials and Electronic Devices 2019; 1(1): 41-45.

[15] Öztürk A. MHD slip flow between parallel plates heated with a constant heat flux. J Thermal Science Technol 2013; 33 (1): 11-20.

[16] Lu B, Xu L, Zhang X. Three-dimensional MHD simulations of the electromagnetic flowmeter for laminar and turbulent flows. Flow Measur Instrument 2013; 33: 239-243.

[17] Sun ZHI, Zhang X, Guo M, Pandelaers L, Vleugels J, Van der Biest O, Van Reusel K, Blanpian B. Strong magnetic field effects on solid-liquid and particle-particle interactions during the processing of a conducting liquid containing nonconducting particles. J Colloid Interface Sci 2012; 375: 203-212.

[18] Nayak MK, Dash GC, Singh LP. Steady MHD flow and heat transfer of a third grade fluid in wire coating analysis with temperature dependent viscosity. Int J Heat Mass Transfer 2014; 79: 741-754.

[19] Muthuraj R, Srinivas S. A note on heat transfer to MHD oscillatory flow in an asymmetric wavy channel. Int Commun Heat Mass Transfer 2010; 37: 1255-1260. 
[20] Anwar Bég O, Sim L, Zueco J, Bhargava R. Numerical study of magnetohydrodynamic viscous plasma flow in rotating porous media with Hall currents and inclined magnetic field influence. Commun Nonlinear Sci Numer Simulant 2010; 15: 345-359.

[21] Bandyopadhyay S, Layek GC. Study of magnetohydrodynamic pulsatile flow in a constricted channel. Commun Nonlinear Sci Numer Simulat 2012; 17: 2434-2446.

[22] Huang H, Li B. Heat transfer enhancement of free surface MHD-flow by a protrusion Wall. Fusion Engineer Design 2010; 85(7-9): 1496-1502.

[23] Aminfar H, Mohammadpourfard M, Maroofiazar R. Experimental study on the effect of magnetic field on critical heat flux of ferrofluid flow boiling in a vertical annulus. Experiment Thermal Fluid Sci 2014; 58: 156-169.

[24] Kefayati GHR. Natural convection of ferrofluid in a linearly heated cavity utilizing LBM. J Molecul Liquids 2014; 191 : $1-9$.

[25] Sheikholeslami M, Ganji DD. Ferrohydrodynamic and magnetohydrodynamic effects on ferrofluid flow and convective heat transfer. Energy 2014; 75: 400-410.

[26] Malvandi A, Safaei MR, Kaffash MH, Ganji DD. MHD mixed convectionin a vertical annulus filled with $\mathrm{Al}_{2} \mathrm{O}_{3}-\mathrm{water}$ nanofluid considering nanoparticle migration, J Magn Magn Mater 2015; 382: 296-306.

[27] Yousofvand R, Derakhshan S, Ghasemi K, Siavashi M. MHD transverse mixed convection and entropy generation study of electromagnetic pump including a nanofluid using 3D LBM simulation. Int J Mech Sci 2017; 133: 73-90.

[28] Bejan A. Convection heat transfer. John Wiley \& Sons, New York, A.B.D., 1995.

[29] Zhao G, Jian Y, Chang L, Buren M. Magnetohydrodynamic flow of generalized Maxwell fluids in a rectangular micropump under an AC electric field. J Magn Magn Mater 2015; 387: 111-117. 